\title{
Narrativas fantásticas: estratégias discursivas no conto "O Gato Negro" de Edgar Allan Poe
}

Daniele Moura da Silveira*1

Monique Mendes Franco**2

\begin{abstract}
RESUMO: Este trabalho tem como objetivo abordar as estratégias discursivas contidas nos textos literários. Inicialmente, pretende-se analisar estratégias contidas nas narrativas fantásticas para em seguida analisar como os elementos discursivos são portadores de efeitos que desencadeiam diversas emoções nos leitores, envolvendo-os na trama literária. Para isso, foi selecionado como corpus de análise o conto "O gato negro" de Edgar Allan Poe. Objetiva-se, ainda, demonstrar a utilização da argumentação nos textos literários, por proporcionar um campo abrangente para a análise de aspectos relevantes sobre a persuasão, formação discursiva e ideológica na narrativa.
\end{abstract}

PALAVRAS-CHAVE: Análise do discurso, estratégias discursivas, formação ideológica, persuasão

\section{Introdução}

A linguagem é um elemento de mediação necessária entre o homem e a sua realidade e como forma de engajá-lo na própria realidade (...) A linguagem é o lugar do conflito, do confronto ideológico, não podendo ser estudada fora da sociedade, uma vez que os processos que a constituem são histórico-sociais. (Foucault)

\section{Sobre a análise do discurso}

A análise do discurso permite várias formas de se trabalhar com a língua sobre diferentes condições de produção envolvendo os discursos e os enunciados, configurando-se como interpretação de olhares que possibilitam desvendar os espaços enunciativos na literatura.

A análise do discurso se fundamenta em três áreas do conhecimento: a lingüística, o marxismo e a psicanálise. No entanto segundo Orlandi (1999) a análise, não aborda somente os campos citados, mas todos os outros que lhe interessam. Para

\footnotetext{
${ }^{1}$ Graduanda em Letras pela Faculdade de Formação de Professores da UERJ/FFP. Bolsista de Iniciação à docência - CETREINA/UERJ; Membro do NUPPE - Núcleo de Pesquisas Políticas que Produzem Educação, membro do Laboratório de Imagem Cinema Paraíso.

${ }^{2}$ Doutora em Comunicação e Cultura. Professora Adjunta do Departamento de Educação da Faculdade de Formação de Professores da Universidade do Estado do Rio de Janeiro (UERJ/FFP).
}

Caderno Seminal Digital Ano 16, nº 13, V. 13 (Jan.- Jun/2010) - ISSN 1806 -9142 
tanto, o objeto de estudo do discurso é a forma de produção de sentido e expressão: “ $O$ discurso é assim palavra em movimento, prática de linguagem: com o estudo do discurso observa-se o homem falando". Contudo a linguagem, dentro da análise do discurso, não é considerada transparente possuindo materialidade simbólica e significativa. Sendo abordados como objetos de análise não só o texto e os elementos contidos neles para compreensão, mas as produções de determinado discurso que compreendem os sujeitos, as situações ${ }^{3}$ vivenciadas e a memória.

\subsection{Formações discursivas e formação ideológica}

A formação discursiva refere-se a um enunciado que possui um sistema de regras predeterminadas. A Análise do Discurso busca estabelecer regras capazes de direcionar as formações discursivas, para determinar os elementos composicionais do discurso como, os tipos enunciativos ou modalidades de enunciação, além dos conceitos e estratégias, logo, estas regras caracterizam a formação discursiva.

De maneira mais abrangente Pêcheux (1988) define a formação discursiva como: "aquilo que, numa formação ideológica dada, isto é, a partir de uma posição dada numa conjuntura dada, determinada pelo estado da luta de classes, determina o que pode e deve ser dito." Assim, o sentido do enunciado é influenciado pela formação discursiva no qual está inserida. Contudo, pode-se inferir que a formação discursiva ocorre em certos tipos de enunciados. Pois, ela ira estabelecer o que se "pode" e "deve" ser dito. Logo toda formação discursiva corresponderá a uma dada formação ideológica.

A formação discursiva representa na ordem do discurso as formações ideológicas que lhe são correspondidas. "O fato de que há um já dito que sustenta a possibilidade do dizer é fundamental para se compreender o funcionamento do discurso e sua relação com os sujeitos e com a ideologia" (Orlandi, 1999). Pois se é na formação discursiva que se determina o posicionamento ideológico de um discurso, as palavras mudam de sentido segundo as posições em que é empregada, isto permite compreender o processo de produção dos sentidos em relação à ideologia.

\footnotetext{
${ }^{3}$ Entende-se como 'situações' o contexto imediato ou amplo levando sempre o momento histórico na época da determinada produção
}

Caderno Seminal Digital Ano 16, nº 13, V. 13 (Jan.- Jun/2010) - ISSN 1806 -9142 


\section{A construção das estratégias discursivas no conto "O Gato Negro" de Edgar Allan Poe}

Por meio da Análise do Discurso, é possível identificar as diversas vozes que compõem e se mesclam ao texto e as enunciações. É por meio da Análise do discurso que será possível identificar os elementos estratégicos contidos na narrativa fantástica para estabelecer uma cumplicidade entre o leitor e a obra.

Para Charaudeau (1999), O sentido discursivo, sob a ótica de quem recebe a mensagem, é muito diferente do sentido lingüístico.

Uma lingüística do discurso integra na sua análise as condições de produção do ato de linguagem e, ao fazê-lo, ela se constrói um objeto multidimensional que opera numa relação triangular entre o mundo como real construído, a linguagem como formasentido em difração, e um sujeito (je/tu) intersubjetivo em situação de interação social. (p. 32)

Dessa forma, o sujeito é considerado um "sujeito cognitivo", pois é capaz de produzir e reconhecer estruturas discursivas. Estabeleceremos então as estratégias discursivas empregadas no conto o gato negro de Edgar Allan Poe, e como essas estratégias são importantes para o nosso cotidiano e não só ao imaginário ficcional.

\subsection{Análise do conto}

No conto de Edgar Allan Poe, o narrador é o protagonista que descreve um fato cujas conseqüências o aterrorizavam. Aparentemente o narrador está preso e Será executado, por este motivo decide escrever uma carta para como ele mesmo afirma: "hoje gostaria de tirar o peso da minha alma"

Em um primeiro momento o protagonista se apresenta como é - um homem bondoso que adora animais e tem como preferido o gato preto denominado "Plutão". Porém, por "influência do demônio da intemperança", o Álcool, seu temperamento e personalidade começam a mudar. Começa, então, a maltratar a esposa e seus animais de estimação menos o gato. Mas sua doença só aumentava "uma noite ao voltar para casa, completamente embriagado [...] pareceu-me que o gato me evitava [...] apavorado pela minha violência." 
Depois de cometer esse ato, enquanto vê o gato se recuperando evitando-o, o protagonista é acometido por remorso. Contudo não durava muito já que pelo fato da bebida um sentimento de irritação crescia e tomado pelo espírito da perversidade, enfocado o gato. Fica clara a preocupação de Poe em desvendar o interior da alma humana em demonstrar que existe uma força irracional e maligna, a qual todos os sujeitos estão propensos a ser acometidos. Evidenciando com isto, o horror que esta dentro de cada indivíduo e pode ser por isso que neste conto não há inferências ao nome do personagem, referindo-se a todos os seres humanos ou ainda mesmo existindo as forças titânicas em nosso inconsciente reconhecido.

$\mathrm{Na}$ noite em que assassinou o gato sua casa pegou fogo, neste instante temos o elemento fantástico sendo introduzido no imaginário dos leitores e do personagem com a finalidade de explicar de forma lógica a mancha na parede e o incêndio, transpassando do gênero fantástico para o estranho. "no dia do incêndio coloca o fragmento do conto"

Durante muito tempo pensou no gato e chegou a sentir falta dele, até que um dia em uma taverna se depara com um gato preto. "[...] Era um gato preto". O personagem o leva para casa e o gato se torna o preferido da mulher, enquanto o para o narrador sentia nojo todas às vezes que o animal se aproximava dele, surgindo rapidamente o ódio, mas lembrava do outro gato o que impedia de maltratá-lo; então o "terror indivisível" começa aos poucos a brotar dentro do homem que diante da presença do gato pensava que era o Plutão que havia reencarnado.

O gato estava sempre atrás dele, o terror ia aumentando. Sua mulher chamavalhe a atenção sobre a mancha que o gato terá debaixo do pescoço, o que o deixou mais assustado ainda: "os contornos da mancha acabaram para se tronar rigorosa"

Neste instante, o protagonista estava beirando à loucura a "criatura" o perseguia dia e noite. Sua consciência não o deixava mais ele começava a ter pensamentos sombrios: “[...] encarnação de um pesadelo de um pesadelo de que não conseguira libertar-me, exatamente pousando sobre meu coração"

Certo dia, acompanhando a sua esposa em afazeres domésticos qualquer no velho prédio em que moravam. Quando estavam na escada, o gato quase o fez cair de cabeça deixando-o furioso "semi-louco de raiva" e conseqüente a essa fúria desenfreada tenta matar o gato, mas a mulher o impede de cometer tal ato de crueldade. "esta intervenção" (procurar no conto esta citação) 
Então, com a mulher morta. Pensa no que irá fazer com o corpo, então decide emparedá-lo, não demonstrando nenhum remorso, como se tivesse decidido mergulhar de vez na crueldade no horror que ele sempre tivera. Depois de emparedar o cadáver da esposa, o protagonista procura quem segundo ele é o causador dessa "desgraça", ou seja, o gato, mas não o encontra em parte alguma, o felino havia desaparecido.

Passaram-se dias e o gato não deu sinal de vida deixando o protagonista muito feliz, estava aliviado que não sentia culpa pelo crime "[...] voltei a respirar como um homem feliz.

No quarto dia, após o crime a brigada da policia foi até a casa e vasculhou tudo em busca da mulher. Porém não a encontrou e quando a policia estava indo embora. Tomado por uma intensa alegria e euforia pelo crime perfeito, queria dizer algo para eternizar o momento.

[...] Senhores - disse finalmente enquanto subiam as escadas Sinto encantado em dissipar as vossas suspeitas [...] a propósito senhores esta é uma casa bem construída" "Então, bate com a bengala na parede, ouve-se um gemido que perpassa todo o porão depois um uivo" um berro crescente, misto de terror e de triunfo.

O policial derrubara a parede e lá está o corpo da mulher e sobre a cabeça dela o gato preto já em decomposição criando uma imagem infernal. Como se pode notar o desfecho deste conto é um elemento importante, pois os fatos convergem para um final surpreendente como afirma o próprio Poe:

E somente com o desfecho constantemente em vista que podemos conferir a um enredo seu indispensável ar de conseqüência ou casualidade, fazendo os incidentes e principalmente em todos dos os pontos, o tom tendam ao desenvolvimento da intenção. (pag.12)

Outro aspecto que podemos notar é utilização de metáforas e comparações que antropomorfizam o gato. Edgar emprega também símbolos, que nos remetem à literatura fantástica. Logo no título temos o "preto", cor que remete ao mundo das trevas. A pureza representada pelo branco, o vermelho remete ao fogo e ao sangue. Já o gato que também tem no conto uma alta simbologia, pois o nome Plutão se refere ao deus do inferno, simbolizando a fatalidade e que possui qualidades mágicas.

Uma possibilidade para a escolha do tema da narrativa pode ter sido as bases supersticiosas que imperavam a idade média, pois as mulheres que tinham relações com

Caderno Seminal Digital Ano 16, nº 13, V. 13 (Jan.- Jun/2010) - ISSN 1806 -9142 
gatos eram as denominadas bruxas, sendo associadas aos demônios. Logo todos esses fazem parte das estruturas das narrativas fantástica mesclando o imaginário e o real.

\section{As estratégias discursivas.}

Já em uma análise mais discursiva pode-se perceber várias estratégias utilizadas pelo autor para desencadear uma gama de sentimentos nos seus leitores por meio de estruturas frasais bem elaboradas.

Evidencia-se no conto "O Gato Negro", resquícios de um discurso de arrependimento e de solidão. Ao iniciar a narrativa com uma frase negativa o enunciador utiliza dentre às estratégias, a formação discursiva. Pois ela irá estabelecer o que se "pode" e "deve" ser dito. Logo, será utilizado aqui o (D1) para o discurso do enunciador do conto e (D2) para o discurso que será transformado:

D1 = "Não espero nem solicito o crédito do leitor para a tal extraordinária e, no entanto tão familiar história que vou contar".

O personagem utiliza-se este recurso para afirmar algo aparentemente negativo, ou seja, aquilo que ele não quer dizer. Temos uma afirmativa com traços de negatividade para expressar um sentimento de indiferença na intenção de mascarar o sentimento de solidão. São discursos omitidos pelo sujeito, pois é justamente o que o enunciador quer. A insistência em negar o fato sugere que na verdade a intenção é convencer e ter a confiança do leitor.

No entanto, se deslocarmos a frase transformando-a em frase afirmativa, retirando a partícula de negatividade "não" e as palavras "nem solicito" teremos aquilo que o enunciador na realidade tenta omitir no discurso anterior. Como podemos observar no segmento abaixo:

D2 = "Espero e solicito o crédito do leitor para tal extraordinária e, no entanto tão familiar história que vou contar".

Com isto, o enunciador pretende comover o leitor trazendo uma visão de imparcialidade tentando persuadi-lo de que não faz parte de sua intenção obter qualquer tipo de aprovação.

\footnotetext{
4 “The black cat", no original
} 


\subsection{O desdobramento dos discursos}

O discurso persuasivo é uma das estratégias utilizada por Poe para envolver seus leitores de tal forma que estes não percebam que estão sendo persuadido a assumirem determinadas posições frente aos fatos narrados. É muito difícil encontrar discursos que não contenham nenhum tipo de persuasão, talvez os que menos tenham sejam os das artes, manifestações literárias ou textos marcados pelos elementos lúdicos. No entanto isto não é indicio de que estejam isentos de discursos argumentativos, pois os textos literários e os elementos lúdicos, ou seja, as artes em geral, também são transmissores de ideologia e verdades mesmos que em um menor grau. Identificam-se três tipos de discursos no conto o gato negro que são: O discurso lúdico, o autoritário e o emocional.

O discurso lúdico de acordo com Citelli é:

[...] A forma mais aberta e "democrática" de discurso. Residiria aqui um menor grau de persuasão, tendendo, em alguns casos, ao quase desaparecimento do imperativo e da verdade única e acabada. Lúdico significa jogo. Seria, pois, um tipo de discurso marcado pelo jogo de interlocuções. (pág.38)

Neste discurso existe um desejo menor de persuadir o leitor, que tem por objetivo "o puro", normalmente sem visar qualquer tipo de persuasão, sendo enfocada apenas a comunicação interpessoal, ou seja, o diálogo. Como podemos observar neste no trecho destacado abaixo:

Meu imediato propósito é apresentar ao mundo, plena, sucintamente e sem comentários, uma série de simples acontecimentos domésticos. Pelas suas conseqüências, estes acontecimentos, me aterrorizam me torturaram e me aniquilaram. Entretanto, não tentarei explicá-los. (pag. 12)

O discurso autoritário é considerado a formação discursiva persuasiva por excelência. Nestes discursos residem todas as condições favoráveis para a dominação por intermédio da palavra. Segundo Citelli (1994), no processo comunicativo autoritário não há possibilidade de interação do ouvinte, não se pode modificar nem interferir naquilo que esta sendo transmitido. "O signo se fecha e irrompe a voz da 'autoridade' sobre o assunto, aquele que irá ditar verdades como num ritual” ( pág.39).

Já o desdobramento discursivo, fica evidenciado com passagem do discurso lúdico para um discurso autoritário, que de acordo com Citelli (1994) não tem nenhuma 
ligação com o discurso dominante ${ }^{5}$, e sim como a imposição da vontade do enunciador sobre o leitor sem lhe dar condições para resposta ou questionamentos. Logo, este discurso influência o comportamento no intuito de obter vantagens, além de ser um mecanismo de representação de poder.

Assim sendo, o narrador inicia a carta expondo a sua primeira intenção que é comunicar "Meu imediato propósito é apresentar [...]", porém no desenvolver da narrativa vai tecendo quase que imperceptível uma estratégia de persuasão ao tentar criar imagens que denotem o seu terror mediante aos acontecimentos. E, ao realizar tal empreitada vai imbuindo nos leitores a noção de que não houve culpa nos atos cruéis, mas se apresenta como vitima das circunstancias que o levou ao desequilíbrio e a insanidade.

Outra estratégia que vale a pena ser destacada é a estrutura do conto que está em formato de carta e contém voz da narrativa na primeira pessoa do singular. Este artifício é um meio para denotar certa informalidade trazendo a proximidade entre o leitor e o conto. Além de estabelecer um diálogo entre o narrador e leitor que compartilha de sua visão e sentimentos, promovendo com isto um discurso literário mais abrangente. Este, por sua vez, é baseado no imaginário que rompe com as leis da realidade. Temos então, outro tipo de discurso estabelecido na narrativa, ou seja, um discurso emocional, transmitindo pelo viés dos sentimentos mais do que os significados contidos no texto fazendo com que o leitor incorpore a seus ideais a ideologia transmitida pelo narrador. Tal tipo de discurso é tão eficaz no ato da persuasão quanto o discurso lúdico e autoritário.

\subsection{Formação imaginária e a construção de identidade}

Outro fator intrigante e a ausência ou o anonimato do nome do protagonista. Este recurso pode ser visto como uma estratégia de envolvimento, pois ao deixar o protagonista sem uma identidade estabelecida, o leitor se colocar na narrativa compartilhando das experiências do narrador, compreendendo os fatos sobre outro aspecto.

Entretanto, Pêcheux denominou a formação imaginaria como um processo resultante de discursos anteriores, se manifestando na discursividade por meio da

\footnotetext{
${ }^{5}$ Entende-se aqui por Discurso dominante como o discurso autorizado que expressa a organização do poder vigente.
} 
relação de sentido. Assim, o emissor projeta a suas representações imagéticas do receptor estabelecendo as estratégias discursivas.

O que ocorre é um jogo de imagens dos sujeitos entre si e dos lugares que estes sujeitos que ocupam na formação social dos discursos já proferido. Temos, então, os jogos na formação imaginária que ocorre quando o narrador relembra sua infância, na intenção de reconstruir uma identidade que venha a desencadear um sentimento de comoção afetando os sentimentos dos leitores. Como no trecho:

Salientei-me desde a infância, pela docilidade e humanidade de meu caráter. Minha ternura de coração era mesmo tão notável que fazia de mim motivo de troça de meus companheiros. Gostava de modo especial de animais e meus pais permitiam que eu possuísse grande variedade de bichos favoritos. Gastava com eles a maior parte do meu tempo e nunca me sentia tão feliz como quando lhes dava comida e os acariciava. Esta particularidade de caráter aumentou com o meu crescimento e, na idade adulta, dela extraia uma de minhas principais fontes de prazer. Àqueles que têm dedicado a afeição a um cão fiel e inteligente pouca dificuldade tenho em explicar a natureza ou a intensidade da recompensa que daí deriva. Há qualquer coisa no amor sem egoísmo e abnegado de um animal que atinge diretamente o coração de quem tem tido freqüentes ocasiões de experimentar a amizade mesquinha e a fidelidade frágil do simples Homem

Com isso, o narrador cria um ambiente de recordação, um lugar de memória. Isto fica evidente com a estruturação dos tempos verbais empregados no passado, "Já na minha infância era notada pela docilidade e humanidade do meu caráter". No entanto, o tempo da enunciação é presente, o emissor mescla os tempos verbais para causar um efeito singular nos leitores, pois utiliza o tempo passado em suas enunciações, narrando o presente que está vivenciando e desta forma projetando os possíveis acontecimentos.

Assim, a voz do passado busca alternativas na narrativa para estabelecer um perfil psicológico e sentimental do protagonista que não tem o nome revelado. Como nos primeiros momentos do conto em que o narrador se apresenta como um homem bondoso que adora animais e tem como o preferido o gato "Plutão", ao qual confere poderes sobre sua personalidade legitimando a força do animal. Aos poucos pode se esquadrinhar um perfil do narrador-personagem por meio de seus discursos. Ou seja, um homem que aparentemente esta presa e será executado no dia seguinte, que decide expor seu ponto de vista de maneira peculiar, uma espécie de carta Testamento, 
confessando de seus crimes, como uma forma de aliviar a sua alma transferindo a responsabilidade de seu ato aos acontecimentos fantásticos ocorridos em sua vida.

\section{Considerações finais}

Observou-se, durante as reflexões, que as narrativas fantásticas e a análise do discurso estão intrinsecamente ligadas, pois na narrativa fantástica podem-se encontrar estratégias que são influenciadoras tanto no que se refere aos elementos que a compõem como: o medo, a hesitação, a dúvida do que é real ou não, quanto à transmissão de conceitos discursivos, persuasivos e ideológicos.

Em um primeiro momento, conclui-se que o texto literário, embora não seja considerada uma fonte portadora de abordagem persuasiva, é um mecanismo de transmissão de ideologias e argumentações que exercem influências nos sujeitos. Mesmo sendo algo esporádico encontramos fontes argumentativas nas narrativas, mascaradas sob um cenário literário de imaginação e irrealidade, que expõem sem imparcialidade a visão da qual se quer imbuir nos leitores, envolvendo-os de forma sutil ou quase imperceptível na tentativa de estabelecer um vínculo de envolvimento com a obra ficcional.

Portanto, é importante ressaltar que este artigo é resultado de uma pesquisa de caráter exploratório e requer ainda inúmeras abordagens, pois as estratégias discursivas e a análise do discurso são campos abrangentes que são permitem variadas interpretações, deixando muitas lacunas.

Enfim, a discussão levantada é o começo para a contribuição do surgimento de outros questionamentos.

\section{Referências bibliográficas}

ALTHUSSER, L. Ideologia e aparelhos ideológicos de Estado. São Paulo: Martins.1974.

BAKHTIN, M. (V. N. Volochínov). Estética da Criação Verbal. São Paulo: Martins Fontes. 1992.

Martins Fontes. 2000.

Os gêneros do Discurso. In: Estética da criação verbal. São Paulo: Questões de literatura e de estética: a teoria do romance. São Paulo:

Hucitec. 1988. 
BARTHES, Roland. O Resumo da língua Tradução. Mario Laranjeiras. São Paulo: Brasiliense. 1988.

BRANDÃO, Helena. H. Magamin. Introdução a analise do discurso. $7^{\mathrm{a}}$ Ed. Campinas. São Paulo: Editora da Unicamp. 1998.

BRUMAN, Zigmunt. O mal estar da Pós-modernidade. Rio de Janeiro: Jorge Zahar editor. 1998.

CERVONI, Jean. A enunciação. São Paulo: Ática 1998.

CITTELI. Adilson. Linguagem e Persuasão. 12a Ed. São Paulo: Ática. 1998.

D'ONOFRIO, Salvatori. Teoria do texto: Prolegômenos e teoria da Narrativa. São Paulo: Ática. 1995.

ECO, Umberto. Seis passos pelo bosque da ficção. São Paulo: Cia das letras. 1994

Obra aberta. Forma e indeterminação nas poéticas contemporâneas. Trad. de Giovanni Cutolo. São Paulo: Perspectiva. 1988.

FURTADO, Felipe. A construção do fantástico na narrativa. Lisboa Horizonte. 1980.

GARCIA, Flavio (org.). A banalização do insólito: questões de gênero literário mecanismos de construção narrativa. Rio de janeiro: Dialogarts, 2007.

GOFFMAN, Erwing. A elaboração da face In: FIGUEIRA, S. A. (org.). Psicanálise e Ciências Sociais. Rio de Janeiro: Francisco Alves. 1980.

KOCH, Ingedore Villaça. A interação pela linguagem. São Paulo: Contexto. 1992.

. Argumentação e Linguagem. São Paulo: Cortez. 1987.

MENDES, Oscar (org.). Ficção Completa: poesias\& ensaios. Rio de Janeiro: Nova Aguilar. 1997

MUSSALIN, Fernanda; Bentes, Anna Christina. Introdução a lingüística: Domínio Fronteiras. Ed. Cortez. 2004.

ORLANDI, Eni Puccinelli. Interpretação: Autoria, leitura e efeitos do trabalho simbólico. Petrópolis, RJ: Vozes, 1996.

. Discurso e leitura. 2a Ed. São Paulo: Cortez.1993.

PECHEUX, Michel. O discurso: Estrutura ou acontecimento. Tradução: Eni Puncinell Orlandi. 3ed. Campinas: Pontes. 2002.

Ed. Da UNICAMP.

Semântica e discurso. Uma crítica à afirmação do óbvio. São Paulo:

REIS, Carlos. Dicionário de narratologia. Lisboa. Almeida. 2000.

TODOROV, Tzvetan. Introdução a literatura fantástica. São Paulo. Perspectiva, 1992. 